\title{
The Annual Performance Review As A Positive Source For Employee Motivation?
}

David L. Mathison, Loyola Marymount University, USA

Vils N. Vinja, Loyola Marymount University, USA

\begin{abstract}
Few places in management literature offer a greater divide between theory and practice than in the Annual Performance Review. Yes, academics have thoroughly researched what the ideal review should look like, yet these authors would argue, as educators and consultants, that we know little on how to really develop and effectively conduct a performance review that serves as a positive source for employee motivation. The purpose of this paper is to call for relevance-a challenge to move from theory to actual practice. Eighty-one practicing managers representing some 23 companies were asked to both assess their ongoing annual assessment and to evaluate a new model of assessment introduced in the present paper. The findings suggest that in the first decade of the $21^{\text {st }}$ century, considerable skepticism remains over almost any model used in the performance review, and this includes skepticism concerning the newly introduced model.
\end{abstract}

The paper concludes with the following three implications of the present study:

1. The harsh realities of the new workplace bring new challenges to employee appraisals.

2. The strength of the employee-supervisor relationship is far more important than the 'correct' assessment method.

3. Any effective motivating performance review must be conducted in a positive work environment marked by the application of best practices.

Keywords: employee appraisal; performance review; annual assessment; new model; relevance; motivation; positive source

\section{INTRODUCTION}

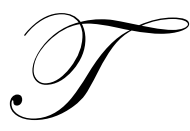

he noble goals of the Annual Performance Review are legendary - "a celebration of a year's success, an opportunity to better align employee performance with the exciting new corporate vision, and a conversation that empowers others to performance levels never thought possible."

However, all too soon, stone-cold reality sets in. The process is not only resisted by many- the manager and the employee alike, but often the performance review becomes simply the most dreaded single event on the annual corporate calendar.

Is there a better way? Should we dump the performance review all together? Are we just doing it the wrong way? Is it the method or the person doing the reviewing? Does the relationship between the reviewer and subordinate significantly help or damage the process? Countless other related questions could also be asked.

The purpose of this paper is to report a research study conducted to directly answer these most critical questions. This paper will first review the traditional models of individual performance reviews and briefly explore why each method may or may not work. Next, a new model of performance review, similar to management objectives but involving peer mentors, will be introduced to research subjects. The results will be reported and the paper will end with a discussion of three important implications for today's practicing HR professionals. 


\section{A HISTORY OF FAILURE}

As early as 1972, Douglas McGregor, a giant in organizational behavior, published a monogram in Harvard Business Review titled, “An Uneasy Look at Performance Appraisal.” Here, McGregor chronicles the all too familiar pitfalls of traditional performance reviews. This included defensive responses of the subordinate, excessive judgmental approaches of supervisors along with the general dread and often avoidance of the entire process. Domske (2010), in a review of problems with performance reviews, argues that mishandled appraisals can lead to "dysfunctional behavior" because they often are manipulative, abusive and autocratic. In an article titled "Performance Reviews," Ashoffner (2010), himself an HR director, speaks of being sued by three employees who were laid off based solely on poorly handled information in their annual performance appraisals.

"Unwanted, Disliked, Dishonest: Performance Appraisal Must Go" was the title of an article written by Rick Dacri (2005) who also argues that we should destroy all performance appraisals, stating, "Employees don't like them, managers hate giving them and they are rarely written honestly anyway." Finally, Manish (2009) simply asks, "Why do we need performance appraisals at all?" He again suggests dropping them all together and simply sitting down and discussing performance issues face-to-face in a normal conversation tone.

\section{SO WHAT ARE THE CORE PROBLEMS WITH ANNUAL PERFORMANCE REVIEWS?}

Bacal (2009), in his article, "Why Performance Appraisals Fail," suggests three problem areas: 1) lack of objectivity on the rater's part, 2) the failure to focus on developmental issues, and 3) fairness issues. Again, in the article, "Dysfunctional Behavior", Domski (2010) argues that most appraisals lack ongoing real-time reviews, genuine employee involvement, and often fail to even recognize good performance. Dacri (2005) even argues that many evaluations are actually downright dishonest and often understate problems in order to avoid the inevitable war of confrontation. Still others would list traditional distortions in perceptions, such as halo-horn effect, contrast effect, primacy recency bias, assumed similarity, and finally, favoring similarity, as major sources of problems in the annual performance review process (Mathison, 1988).

\section{THE ALTERNATIVE MENTORING TEAM PERFORMANCE APPRAISAL: A BETTER MOUSE TRAP?}

\section{The Model}

Vinja and Mathison (2009), in an unpublished monograph titled "The Career Board Performance Appraisal System", introduced a fresh approach to the appraisal system which may serve at the "Third Way." Here, avoiding the age-old problem of one personality verses another and the tensions inherent in a power differential, the introduced method is similar to traditional management by objectives (MBO); however, it also includes a mentor team of peers or fellow managers. Goals are employee generated and quarterly progress is reviewed. Active listening is the hallmark as the subordinate reviews, in an informal presentation, their personal assessment of the past quarter's performance.

\section{The Goal}

The goal is to empower employees by encouraging them to take control of their own careers. This involves partnering with peers and immediate managers and aligning individual goals with the organization's goals.

\section{The Process in Steps}

1. The immediate supervisor communicates to the employee the broad parameters of the job and the annual goals of the team/division/organization.

2. Employees select two people, in addition to their manager, to serve on their mentor career team. These people may be peers within the organization or other managers, but it is up to the employee to choose these two. The two mentor positions are held for a minimum of one year. If an employee is new to the organization and does not yet know anyone, the two mentor members may be assigned. 
3. The given employee, having developed individual goals in concert with the supervisor, presents the goals to the team. Quarterly, the employee will report to the career team on her/his progress.

4. The Career Mentor Team will actively listen to the presentation and provide constructive feedback and further guidance during this presentation.

\section{Responsibilities}

1. Manager - The manager maintains all her/his existing level of authority.

2. Career Mentor Team Members - Act as an advisory/mentor role only. They provide direction, feedback and support, but do not have any line authority over the employee.

\section{Advantages}

1. Employee is Empowered - This builds on the proven value and success of a Management by Objectives (MBO) management assessment system (Bratton \& Gold, 2008). There is a partnering with the employee to develop their own goals within the context of the unit and to develop her/his own strengths. Also, this builds on a mentor system; for example, as used by General Electric (Welsh, 2005) where part of one's assessment is how well the person you are assigned to mentor performs a line of responsibility.

2. Reduces the Tensions Inherent in the Manager-Employee Annual Review - Now with a Mentoring Team (Brenner, 2007; Murray, 2000; and Harish et al., 1993), some of the avoidance and management impulse to understate performance problems (Welsh, 2005) may be softened. The manager now also has a partnering team in supervision of the given worker.

3. Professions/Exposure to the Larger Organization - Clearly, especially early in one's career, the more your skills are known to the larger organization, the faster one's career is likely to advance (Bratton \& Gold, 2008). Additionally, this semi-public announcement of one's unique goals may draw additional support of resources within the group or organization.

\section{METHOD}

\section{Subjects}

Eighty-one business professionals participated - 47 males and 34 females. About $56 \%$ had less than ten years' work experience, $29 \%$ were mid-career, and about $15 \%$ had 20 or more years' work experience. Thirty-one percent were managers and $9 \%$ were senior executives, with the balance being skilled professionals. Thirty-five percent worked for companies that employ fewer than 100 employees and the remaining $65 \%$ worked for firms employing between 100 and 1,000 employees.

\section{Procedure}

All eighty-one subjects answered an online survey (Appendix1) which included both Likert-like and openended questions. An online survey was chosen because of its ease in administering and evaluation, plus it maximized confidentiality.

\section{The Questionnaire}

The questionnaire was designed for accessibility, quick understanding and brevity. A well written and brief paragraph described the Mentoring Team Performance Appraisal Model. This was followed by nine highly focused questions:

1. Do employees view themselves as being in charge of their own career?

2. Do performance appraisal systems have: 1) No impact; 2) A small impact; or 3) A large impact on employee commitment to their company?

3. Does the impact of the performance appraisal system on employee commitment to the company vary by level with the organization? 
4. During down economic times, does a performance appraisal system have a greater impact on the commitment of an employee than during good economic times?

5. Does an employee's relationship with his/her manager affect the employee's opinion of the performance appraisal system being used?

6. Do companies solicit feedback from employees on their performance appraisal system?

7. How satisfied and committed would employees be if they worked for a company that used the Mentoring Team Performance Appraisal System?

8. What is the most important factor in the success of the Mentoring Team Performance Appraisal System?

9. How can the Mentoring Team Board Performance Appraisal System be changed to be more effective?

\section{Statistical Method}

Standard deviation tests, along with two-tailed T-Tests, were applied to the Likert-like questions. P-values were also calculated. Also, factor analysis was conducted and after the Varimax Rotation (Cureton \&Milzik, 1974), four broad factors were revealed.

\section{RESULTS}

For the sake of brevity, the following is a summarization of the relevant statistical results:

1. Small companies are more likely to have concerns over professional development than large companies.

2. Rank within a company appears not to be linked to how committed one is to the success of the appraisal system.

3. No matter which appraisal system is used, the actual method has little effect on one's commitment to the company. The individual supervisor's positive relationship with the employee appears to be a far more significant factor.

4. Employees tend to express more commitment to the appraisal system in smaller corporations.

5. There is a significant positive correlation between liking the existing appraisal system and liking the same company.

6. Subjects reported that the health of the national economy had little or no impact on how the Performance Appraisal system was viewed.

7. Subjects did not feel that the Mentoring Team Performance Appraisal Model introduced in the present paper would have any significant impact on their commitment to the company.

\section{DISCUSSION}

This vein of research seems forever doomed. The lack of any significant findings on which appraisal system works better than another in the present study appears to just drive nails deeper into this coffin. Yes, the subjects seemed to favor small companies' appraisal systems over larger ones; and if the subjects liked the company, they would tend to also favor the appraisal system. However, what is most significant about this study is what tended to wash out as important among the subjects. For example, the position within the company - be it the line worker, manager, or top management - seemed to have little impact in this present study on the success of an appraisal system. Which appraisal system used also seemed to have little effect on the success of the annual appraisal in a company. Subjects also reported the state of the economy had little impact on the success of the appraisal system. Most significant to this study, the newly introduced Mentoring Team Performance Appraisal Model was felt to have almost no impact on the possible success of an appraisal system.

Where does that leave this study? In fact, even when most of the predicted findings prove insignificant, one has still learned something. Clearly, the findings in this present study suggest that the relationship between the supervisor and the employee is far more important than the method used in the appraisal interview. Or worded differently, the employees' relationship with the supervisor, whether positive or negative, may be the most significant factor in the success of a performance appraisal interview. It is also noteworthy that none of the subjects suggested that the appraisal process should be abandoned - only improved. 


\section{IMPLICATIONS}

The purpose of this study was to look at the Annual Performance Review as a positive source for employee motivation. The question was asked, "What works and what doesn't work?" After reviewing the literature in this area, which suggests very little optimism was warranted, a new model called "Mentoring Team Performance Appraisal" was introduced. Again, most of the eighty-one subjects used in this present study indicated this new method was little improvement over past failed methods. The one significant finding was that the quality of the supervisor/employee relationship seems to be one of the only significant factors that may predict effective performance appraisal. This healthy relationship may be one of the few positive sources for employee motivation in the appraisal process. This one finding has led to three important implications in this study relevant to HR professionals and the appraisal process:

1. The Harsh Realities of the New Workplace Brings New Challenges to Employee Appraisals

Now called the "New Social Contract", (Bengston, 2003) argues there has been a fundamental shift in an employee's relationship with the corporation in recent years. Gone is loyalty and job security. The new mantra is a "faster, cheaper, better" work environment. The worker is now viewed as a "free agent" who is contracting her services for an understood finite period of time. The net result is a new skepticism in 2010 between the employee and the company. This may, in turn, add a sour dimension to the hope for a positive employee appraisal system. Does this faceless company really care about my future employment with them? Why bother?

2. The Strength of the Employee-Supervisor Relationship is Far More Important than the "Correct Method"

As the CEO and Chairman of General Electric, Jack Welsch, was asked, "What do you spend most of your time doing at GE?" He replied, "I'll spend 10\% of my time developing people. I hire the best people possible and then pump those full of self-confidence" (Welsch, 2005). He was also famous for annually firing GE's bottom 10 percent, arguing "most annual assessments are lies" and evaluating on the "4-E's energy, energize others, edge, and execute". Jack Welsch clearly focused much of his energy on annual reviews and argued in his book, Winning (2005), "Whatever the method of assessment, be it the $360^{\circ}$ or his 4-E's, the employee will beat it within two years." Correctly, he said the annual review just gets the conversation going. At the heart of any truly motivating and empowering annual assessment is not the method, but the relationship - a relationship that is marked by positive interactions and an ongoing active dialogue, combined with an organizational environment that is focused on best practices in HR. The final key to the puzzle on how a performance review becomes a positive source for motivation lies in the application as HR best practices.

3. Significant Positive Relationship Between the Supervisor and Employee Combined with a Corporate Climate Marked by the Application of HR's Best Practices seems to be the Key Factor:

- Choose wisely - hire the best people the corporation can afford.

- Empower these people by pumping them full of self confidence.

- Show them what success looks like; be clear on expectations.

- Measure performance accurately in a performance-oriented work environment.

- Finally, reward them generously and have a clear connection between performance and pay.

\section{CONCLUSION}

Managers hate to give them and employees hate to receive them - almost universally; the annual performance review is loathed by the CEO and the lowest line worker alike. At best, it is viewed as the necessary evil of HR. Yet, also universally, most would agree that accountability and feedback are an essential factor in the performance equation. This paper argues that in 2010, the challenge of developing a positive review environment is twice as difficult because of the "new social" contract where "free agent" rules over loyalty. However, this paper also argues that productive and positive annual reviews begin with a healthy positive relationship and continuous dialogue between the employee and supervisor, all within the context of a consistent application of HR Management 
Best Practices. While not the magic bullet, this is certainly the beginning of the annual review as a positive source for employee motivation. It is where we need to start.

\section{AUTHOR INFORMATION}

David L. Mathison is Professor of Management at Loyola Marymount University, Los Angeles. Prior to joining LMU he served on the faculty of Indiana University and Utah State University. His teaching interests include Business and Society, Corporate Leadership and Power within the Organization. He has some 60 published articles and was nominated for "Professor of the Year" by the LMU community in 2010.

\section{REFERENCES}

1. Achenbaum, W. et al. (2003). The Changing Contract Across Generations, Hawthorne, NY: Aldine De Groyter.

2. $\quad$ Armstrong, S. et al. (2003). Stress Free Performance Appraisals, Franklin Lakes, NJ: CareerPress.

3. Ashoffner, A. (2007). Performance Reviews, www.oppapers.com/essays.

4. Bacal, E. (2010). "Ten Stupid Things Managers do to Screw up Performance Appraisal," http.work911.com/performance.htm.

5. $\quad$ Bacal, E. (2010). Why Ratings Based Appraisals Fail, www.work911.cp/performance.htm

6. Bourne, M. et al. (2002). The Success and Failure of Performance Measurement Initiatives, International Journal of Operations and Production Management, 22(11), 1288-1310.

7. Bratton, J. et al. (2007). Human Resource Management, $4^{\text {th }}$ ed., London: Palgrave, McMillan.

8. $\quad$ Brenner S. (2007). "The Mentoring Team Approach: A New Concept in Undergraduate Teacher Education," Teacher Education and Special Education, 10(1), 26-30.

9. Coens, T. et al. (2002). Abolishing Performance Appraisals: Why They Backfire and What to do Instead, San Francisco: Berrett-Koehler.

10. Cureton, E. et al. (1974). The Weighted Varimax Rotation and the Promax Rotation, Psychometrika, 40(2), $183-195$.

11. Dacri, R. (2005). Unwanted, Disliked, Dishonest: Performance Appraisals Must Go, Your Business, Blethen Maine Newspapers, 2005.

12. Daniel, R. et al. (1979). Consequences of Individual feedback on Behavior in Organizations, Journal of Applied Psychology, 64(4), 349-371.

13. Domske, L. (2008). Some Problems with Performance Appraisals, Research papers, www.oppapers.com/essays.

14. Domske, L. (2010). Dysfunctional Behavior, Research papers, www.oppapers.com/essays

15. Editor (2010). Challenges of Performance Appraisal, Appraisals. Naukribub.com/challenges.html

16. Editors (2010). The Problems Inherent in Performance Appraisal www.openlearningworld.com

17. Editor (2010). 10 Secrets to an Effective Performance Review, http.www.businessmanagementdaily.html

18. Eskildsen, J. et al. (2006). Enhancing importance - Performance Analysis, International Journal of Productivity and Performance Management, 55(1/2), 21-40.

19. Manish, A. (2008). Why do we need Performance Appraisals, Research papers, www.oppapers.com/essays

20. Menefee, J. et al. (2006). The Role of Human Resources in the Success of New Business, Southern Business Review, 32(1), 13-23.

21. McGregor, D. (1972). An Uneasy Look at Performance Appraisal, Harvard Business Review, 50(5), 133 138.

22. Murray, B. (2001). Mentor teams ease dissertation dread, APA Monitor 28(5).

23. Neely, A. et al. (2001). The Performance Prism in Practice, Journal of Measuring Business Excellence, 5(2), 6-13.

24. Patterson, T. (1987). Refining Performance Appraisal, Journal of Extension, 25(4), 5-12.

25. Schwartz, A. (2010). The How-To's of Effective Performance Appraisals, http//www.ralah.com/

26. Simmons, A. (2003). When Performance Reviews Fail, Emerald Management Review, 57(9), 47-53.

27. Welsch. J. (2005). Winning, NY, NY: Harper Business.

28. Wood, S. (2003). Human Resource Management and Performance, International Journal of Management Reviews, 1(4), 367-413. 


\section{APPENDIX I - SURVEY}

\section{Welcome}

This survey is part of a research project being conducted at Loyola Marymount University in Los Angeles, CA. All submissions are anonymous and the results will only be used for analysis that will be included in a research report. If you have any questions or would like to discuss this topic, please send an email to nils_vinje@yahoo.com.

We are very interested in your opinion on performance appraisals. If you are not currently employed, please use the experience from your most recent company to answer the following questions. Please SELECT the option that BEST represents your opinion.

Estimated Completion Time $\sim 10$ Minutes

Please Click Next to Continue

\section{Section I-Page 1}

Please SELECT the option that BEST represents your opinion.

\section{* 1. What level are you in your career?}
Early (Less than 10 years working)
Middle (Between 10 and 20 years working)
Adranced (More than 20 years working)

* 2. I am the CEO of my own career. I am responsible for setting the vision for my career and creating a plan to execute on that vision.

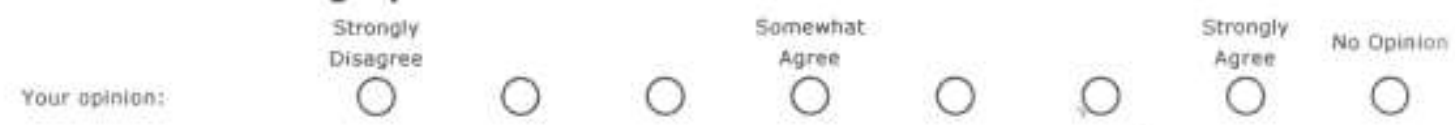

* 3. How would you describe your relationship with your current manager?
Your Opinion:
Poor
Good
Great
Idon't have
$\bigcirc$

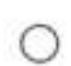
O
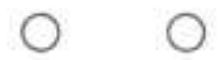
a manager

* 4. How would you describe the commitment of your company to developing its employees?

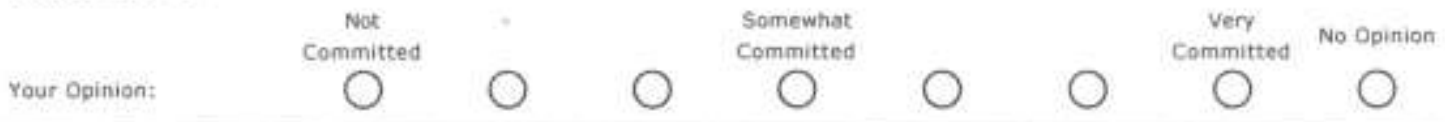

\section{Section I - Page 2}

* 5. Does your company use a performance appraisal system to measure employee performance on a regular basis (i.e. annual, semi-annual, quarterly etc.)?

Yres

No

\section{Section I-Page 3}


Please SELECT the option that BEST represents your opinion.

* 6. For some people, the appraisal system used by their company has a large impact on their commitment level to the company. For other people, the appraisal system has little or no impact on their commitment level to the company. How much of an impact does your company's performance appraisal system have on your commitment to your company?
Your Opinion:
No Impact
$\mathrm{O}^{2}$
O
$\overbrace{}^{\text {Small Impact }}$
$\bigcirc$
arge Impact No Opinion

* 7. The performance appraisal system used by my company has (a) on my commitment to my company.
Negative
Impact
Your Opinion:
(
O
No Impact
Positive
Impact
No Opinion

* 8. I think the performance appraisal system used by my company is
Your Opinion:
poor
Good
(
0

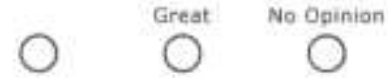

* 9. After going through the performance appraisal process, I feel to my company.
Your Opinion:
Not Committed
O

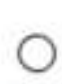
O
Somewhat
Committed
Very Committed
No Opinion

\section{Section I-Page 4}

Please SELECT the option that BEST represents your opinion.

* 10. What level of impact does your company's performance appraisal system have on your commitment to your company depending on the following economic conditions?

GOOD Economic Times
AVERAGE Economic Times
Difficult Economic
Times

* 11. Does your company ask for feedback on how the performance appraisal system can be improved?
Yres
№

\section{Section II - Page 1}

Below is a description of a new performance appraisal system. Please read the steps outlined and answer the following questions. 
Steps of the Career Board Performance Appraisal System:

1) Managers communicate to their employees the goals of the group/division/organization.

2) Employees select two people in addition to their manager to serve on their Career Board. These people can be peers or other managers, but it is up to the employee to choose these two positions. The two Board positions are held for a minimum of one year. If an employee is new to the organization and does not yet know anyone, the two board members can be assigned.

3) Employees present their goals and progress quarterly through a presentation to their Career Board.

4) The Career Board actively listens and provides feedback during the presentations.

Roles and Responsibilities

1) Manager - The manager maintains his/her existing level of authority. The manager will take into account the feedback from the other career board members when it comes time to assign a formal measure to an employee's growth.

2) Career Board Members - Fulfill an advisory role only. They provide direction, feedback and support, but do not have any authoritative power over the employee.

Note: Compensation is handled at a separate time and through a separate process. The results of this system will be used during the compensation review and award process. However, this appraisal system is designed for employee development only.

Imagine you are an employee in an organization that uses the Career Board Performance Appraisal System and please answer the following questions.

* 12. How effective do you think this system would be as an employee development tool?

Your Opinion: Not Effective:

* 13. How satisfied would you be with the Career Board Performance Appraisal System as an employee development tool?
very
Somewhat
Satisfied
very
satisfied
No Opinian
Your Opinion:

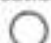
$\mathrm{O}$
O
O
0
0

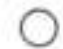

* 14. What kind of impact would the Career Board Performance Appraisal System have on your commitment to your company?
Negative
tmpact
No Impact
Posative
No Opiaion
Your Opinien:
O
0

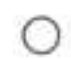
0
0
impact

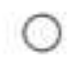

* 15. Would you be willing to dedicate up to one hour per quarter to serve on a colleague's career board?

Your opinion:


* 16. In your opinion, what is the MOST important factor in the Success of the Career Board Performance Appraisal System?

Commitment from management.

It is used throughout the organization at all levels.

Managers and career board members are properly trained on how to give constructive feedback and listen.

All of the above

other (olease specify)

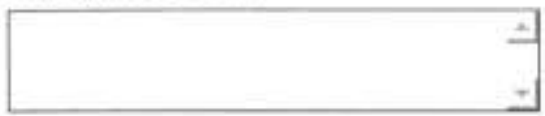

* 17. Please give some suggestions on how you think the Career Board Performance Appraisal System could be improved?

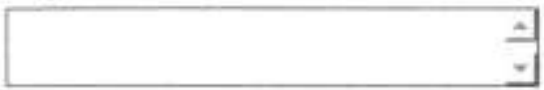

\section{Section III - Page 1}

Please SELECT the option that BEST represents your opinion.

* 18. What is your Gender?

Male

Female

* 19. What level is your current position?
Employee (Non-Manager)
Manager
Director
Vice President
Executive
other, please speciry

* 20. How many employees are in your company?
Less than 50
Between 51 and 100
Between 101 and 250
Between 251 and 500
Between 501 and 1,000
Greater than 1,000 